\title{
Introduction on the Importance of Engineering Survey in Project Management
}

\author{
Yanlei Meng*, Guiming Chen, Mi Sun, Zhipeng Sun and Weigang Gao \\ Department of Management, High-Tech Institute of Xi'an 710025, Shanxi, China \\ ${ }^{*}$ Corresponding author
}

\begin{abstract}
During the construction of the project, all surveying and mapping work is collectively referred to as engineering survey. Therefore, the measurement work contains a wide range of content, in the engineering survey, design and construction management stage are involved. To the actual work, the project measurement runs through the project building in a number of stages, and provide basic services. This paper mainly through the analysis of engineering measurement at all stages of the role played by the measurement work in the project management work to do the following description.
\end{abstract}

Keywords-engineering measurement; project management; construction quality; function

\section{ENGINEERING SURVEY}

\section{A. Definition of Engineering Measurements}

According to the information, as well as the daily work of the commonly known, the general definition of engineering measurement as: construction of all mapping work can be collectively referred to as engineering measurement. It is in the construction of the construction process of the survey, design and operation and management of a series of engineering stages to provide the basis of the service work, but also all the basic work of the construction process. No measurement of the data as a basis for reference, any construction process and construction can not be further carried out.

\section{B. Classification of Engineering Measurements}

Engineering survey According to the order of work and nature, can be divided into the following stages: survey and design stage engineering survey and topographic measurement, construction phase measurement and equipment installation measurement, completion and management phase measurement. In terms of the macro point of view, the measurement of construction work not only in the construction of the national economy is reflected, but also in the various departments of national defense construction can reflect its importance

\section{Engineering Measurements Are Included in the Order of Their Work}

Engineering construction planning and design phase of the measurement work. At this stage, the main map is to draw more reliable reference data. In addition, the need for engineering geological exploration, hydrogeological exploration and other measurement work. For important but not geologically poor areas, the stability of the formation needs to be observed accordingly.

The construction of the construction phase of the measurement work. After each project's project is submitted for approval, it is possible to enter the construction phase. At this time can be based on the general requirements of the building, in the field to be calibrated to serve as a reference in the actual work. At the same time, according to the site of the project in the terrain and the nature of the project to establish a different construction control network for the alignment and lofting to provide basic work. And then according to the modern new scientific way off the line, according to the design drawings to design the actual engineering buildings. engineering construction management and measurement work. During the management of the project, in order to ensure the safety of the building, it is necessary to accurately observe the various aspects of the building, such as the structure of the subsidence, tilt, etc., and can timely obtain the required data, and then Effective analysis. Therefore, the engineering survey can serve as a basic measurement work, serving the entire project period of multiple stages.

\section{THE IMPORTANCE OF ENGINEERING SURVEY IN PROJECT MANAGEMENT}

\section{A. The Role of Engineering Survey in the Construction Quality and Construction Stage of the Project}

Before the construction of the construction, the first building in the actual construction of the lofting positioning for the next step to provide preparation. This work plays a very critical role. For the measurement of the accuracy requirements are relatively high, for the success of the entire project has a more closely linked. In the construction phase, the construction of the foundation pile requires more accurate measurement results, to ensure that it meets the requirements of measurement. In the construction of the provisions of the provisions of the requirements for the pile of pile position of its accuracy is extremely accurate, do not allow a greater deviation. Otherwise it will lead to pile void, increase the project's financial budget. Once the situation encountered in the pile of void, the need for re-fill the pile work. This will not only affect the progress of the project, but also affect the pre-budget data, affecting the overall quality of the project. In the construction, when it comes to the base plate foundation construction, the need to avoid the soil below the working surface of the free excavation 
to ensure that the cushion of the soil density, and thus to ensure the quality of construction.

\section{B. Engineering Survey in the Main Structure of the Construction Phase}

The impact of the quality of the project on the construction of the main structure of the construction phase can be mainly reflected in the following aspects: the control of the wall column, the vertical control of the building and the control of the flatness of the building. Among them, the accuracy of the measurement of the plane of the studs will be directly related to the overall verticality of the building, and the effect on the barbed steel banding and the quality of the template is also more serious.

\section{The Role of Engineering Survey in the Construction Phase of the Project}

The building needs to be perfected to finish the construction phase and eventually become a usable building. At this stage, it is not only necessary to complete the work that needs to be completed at this stage, but also to identify the quality or safety issues left over from the previous period and to take appropriate measures to correct them. Therefore, the technical level of this measurement work and the accuracy of the work will also directly affect the overall quality of the project.

\section{Project Construction and Operation During the Deformation of the Project for the Project Play A Role}

In the construction of the construction process, the settlement observation of the building has a very important role. Through the observation to obtain the latest data, and according to the actual situation of the building of its data for effective analysis and research, and according to the problem to take appropriate measures to ensure the safety of buildings

\section{E. Engineering Measurement on the Prevention and Treatment of Quality Prevention of the Role of Common Disease}

In the construction project, the common project quality problems are mainly steel, templates, concrete and other aspects, specifically to the engineering measurement of the main line for the content is: steel deflection, the concrete surface of the light and the external walls of the vertical and horizontal works Wait.

\section{CONCLUSION}

Engineering survey work in terms of civil construction and construction, with its own characteristics. First, the quality of construction and engineering survey work directly linked to the level of measurement staff directly affect the engineering survey results and accuracy. Secondly, the choice of engineering construction program, for the measurement of the accuracy and progress have a very important impact. Third, the quality of the project is good or bad, will also be affected by the workplace environment. As in the process of construction of the mechanical vibration and welding operations, the scene of the brightness and weather and weather are its direct work has a more significant impact, such as measuring the angle and the accuracy of the measurement distance. Fourth, the error of measuring instruments, through a number of practical work experience should also be taken into account to prevent the adverse effects of excessive errors. Fifth, because the concrete by external factors (temperature, moisture) and other effects, will produce deformation or telescopic lamp situation, so in the actual measurement should also be considered. At the same time, we in the actual work process to be aware of the important role of engineering measurement work, scientific management of the actual work encountered in the measurement of technical problems, do the basic work of measurement work to improve the project management In the engineering quality, for the safety and use of the owners to provide a good protection and services, through technical means to ensure the quality of construction works to achieve the construction project and project management stage of scientific and reasonable monitoring, to avoid accidents caused by the staff and property loss.

\section{REFERENCES}

[1] Zai Dong-dong, Hou Yue. Discussion on the Importance and Countermeasure of Construction Quality Management in Construction Engineering [J]. China 's new technology and new products, 2016(12). (in chinese)

[2] Wu Hong-tao. Study on Construction Quality Management and Control of Construction Engineering [J]. Building materials and decoration, 2016(13). (in chinese)

[3] Hu Wu-sheng, Gao Ceng-fa. Principle of GPS Survey and Its Application [M]. China Communications Press, 2002. (in chinese)

[4] Wang Ming-xuan. Application and Prospect of New Technology of Surveying and Mapping in Engineering Survey [J]. Resource Information and Engineering, 2016(02). (in chinese)

[5] Wang Yuan-long. Discussion on Problems and Countermeasures in Engineering Survey[J]. Science and Technology Innovation, 2010(34). (in chinese)

[6] Wang Dan. On development of engineering surveying in the era of information [J]. Geotechnical Investigation and Surveying, 2009(6). (in chinese) 